\title{
Corrosion Behaviour of Stainless Steel 304 Electroplated with Zinc Followed by Blue Passivation
}

\author{
H.B. Sherine, ${ }^{*}$ ' C.C. Rajakumari ${ }^{1}$ and S. Rajendran ${ }^{2}$ \\ ${ }^{1}$ Department of Chemistry, Holy Cross College, Tiruchirappalli - 620 002, Tamilnadu, India \\ ${ }^{2}$ Department of Chemistry, GTN Arts College, Dindigul - 624 005, Tamilnadu, India
}

Received 3 December 2010; accepted 12 March 2011

\begin{abstract}
The corrosion resistance of three stainless steel materials, namely, stainless steel (SS), stainless steel electroplated with zinc (SS-Zn) and stainless steel electroplated with zinc followed by blue passivation (BP), has been evaluated in an aqueous solution containing $3.5 \% \mathrm{NaCl}$. A potentiodynamic polarization study and AC impedance spectra have been used to investigate the corrosion behaviour of these metals. The corrosion resistance of these materials in $3.5 \% \mathrm{NaCl}$ increased in the following order: $\mathrm{SS}>\mathrm{SS}+\mathrm{Zn}+\mathrm{BP}>\mathrm{SS}+\mathrm{Zn}$.
\end{abstract}

Keywords: decolourisation, corrosion prevention, electroplating, blue passivation.

\section{Introduction}

The development of the chemical, fertilizer, petrochemical, refining and energy industries depends in most cases, on resolving the problems associated with the use and maintenance of stainless steel [1]. The most important problem faced with the use of stainless steel is intergranular corrosion (IGC). The IGC resistant stainless steel was achieved by stabilizing the characteristics of the steel decreasing its percentage of carbon to a very low level [2]. Characterization of oxide films formed on metals and alloys has been subject of study for many years, because the physical and chemical properties of oxide films can alter the mechanism and kinetics of the corrosion processes [3-5]. Particularly, the characteristics of oxide films formed on type 304 stainless steel and carbon steel as nuclear power plant materials have been subject of investigations, to understand environment related materials failure problems. Intergranular stress corrosion cracking (IGSCC) of Type 304 stainless steel has been a major concern in boiling water reactors undergoing normal water containing 100 to $300 \mathrm{ppb}$ of oxygen, 200 to $500 \mathrm{ppb}$ of $\mathrm{H}_{2} \mathrm{O}_{2}$ and $<10 \mathrm{ppb}$ of hydrogen. Self-organized porous structures produced by anodization of metals or semiconductors have

\footnotetext{
* Corresponding author. E-mail address: beni2@ rediffmail.com
} 
attracted much attention regarding applications [6-14]. The composite electroplating allows to co-deposit fine particles of metallic or non-metallic compounds into plated layers to improve the surface properties and compare the performance of pure nickel and $\mathrm{Ni}-\mathrm{SiC}$ nanostructured composite coatings, and the results indicated that the co-deposition of nickel and $\mathrm{SiC}$ nano particles leads to uniform deposits possessing better abrasion, wear and corrosion properties [15].

The present study is undertaken (i) to electroplate zinc on stainless steel surface in an electroplating unit, using zinc anode and a bath containing zinc chloride, potassium chloride and boric acid; (ii) to do blue passivation on the zinc plated carbon steel surface; (iii) to study the corrosion resistance behaviour of the above electroplated surface (a) by immersing it in an aqueous solution containing $3.5 \%$ of $\mathrm{NaCl}$, (b) by placing a drop of $\mathrm{CuSO}_{4}$ solution on the metal surface, and (c) by polarization study, AC impedance spectroscopy and cyclic voltammetry; and (iv) to decolourise methyl orange solution using (a) stainless steel, (b) stainless steel electroplated with zinc, and (c) stainless steel electroplated with zinc followed by blue passivation.

\section{Experimental}

\section{Preparation of the specimen}

Three metal specimens, namely, stainless steel (SS 304), stainless steel coated with zinc, and stainless steel coated with zinc followed by blue passivation, were chosen for the present study. Stainless steel and stainless steel coated with zinc are compared with stainless steel coated with zinc followed by blue passivation. The composition of SS 304 was (wt\%) $10 \mathrm{Cr}, 8 \mathrm{Ni}, 0.80 \mathrm{Mn}, 0.044 \mathrm{C}, 0.0025 \mathrm{P}$, $0.0015 \mathrm{~S}$ and the balance iron [16], and specimens with the dimensions of $1.0 \times 4.0 \times 0.2 \mathrm{~cm}$ were used for electroplating and to measure the corrosion resistivity of the metal surface by weight loss method.

\section{Method of electrodeposition}

The process of electroplating the stainless steel specimens involves pickling with con. $\mathrm{HCl}(16 \mathrm{~N})$, washing with distilled water, drying, polishing, degreasing with cleaning powder containing soda, chalk and nice emery powder, drying and immersing in bath solution. The composition of the bath solution for zinc plating was $\mathrm{ZnCl}_{2}(100 \mathrm{~g} / \mathrm{L}), \mathrm{KCl}(225 \mathrm{~g} / \mathrm{L}), \mathrm{H}_{3} \mathrm{BO}_{3}(40 \mathrm{~g} / \mathrm{L})$. For electrodeposition, pure zinc plate acts as anode and stainless steel specimen acts as cathode. The process was carried out at room temperature $\left(35^{\circ} \mathrm{C}\right)$ and no agitation of the bath solution is required. DC current was passed for the required time (5 minutes). After electrodeposition the specimen was washed with water and dried [17].

The composition of the post treatment bath solution for blue passivation was 200 $\mathrm{g}$ of sodium dichromate and $5 \mathrm{~g}$ of $\mathrm{KCr}\left(\mathrm{SO}_{4}\right)_{2} \cdot 12 \mathrm{H}_{2} \mathrm{O}$ (chrome alum). $4 \mathrm{~g}$ of this mixture were dissolved in $10 \mathrm{~mL}$ of nitric acid and made upto 1 litre with water. The zinc plated stainless steel was immersed in the blue passivation bath for one minute. Then the metal specimens were dried. 


\section{Measurement of corrosion resistance of the electroplated metal surface}

The following studies were used to measure the corrosion protective nature of the film formed on the stainless steel surface after electroplating.

\section{Immersion in chloride environment}

The metal specimens in triplicate were immersed in $100 \mathrm{~mL}$ of an aqueous solution containing $3.5 \%$ of $\mathrm{NaCl}$ for a period of one day. The weights of the specimens before and after immersion were determined using a digital balance. The corrosion rate $(\mathrm{CR})$ was calculated using the equation

$\mathrm{CR}=$ (weight loss in $\mathrm{mg}) /\left(\right.$ surface area in $\mathrm{dm}^{2} \times$ immersion period in days $) \mathrm{mdd}$

\section{Action of 1\% copper sulphate solution}

One drop of $1 \%$ copper sulphate solution was placed on the surface of the metal. The time taken for the formation of a red solution was measured, because it is an indication of the rate of electron transfer (corrosion process) from the iron to the $\mathrm{Cu}^{2+}$ ion on the metal surface.

\section{Potentiodynamic polarization study}

Polarization study was carried out in $\mathrm{H} \& \mathrm{CH}$ electrochemical workstation impedance Analyzer Model CHI 660A provided with iR compensation facility, using a three electrode cell assembly. Stainless steel(SS), stainless steel coated with zinc $(\mathrm{SS}+\mathrm{Zn})$, or stainless steel electroplated with zinc followed by blue passivation $(\mathrm{SS}+\mathrm{Zn}+\mathrm{BP})$, were used as working electrode, platinum as counter electrode and saturated calomel electrode (SCE) as reference electrode. The corrosion parameters such as linear polarization resistance (LPR), corrosion potential $\left(E_{\text {corr }}\right)$, corrosion current $\left(I_{\text {corr }}\right)$ and Tafel slopes $\left(b_{c}\right.$ and $\left.b_{a}\right)$ were calculated.

\section{Alternating current impedance spectra}

AC impedance spectra were recorded in the same instrument used for polarization study, using the same type of three electrode cells assembly. The real part (Z') and the imaginary part (Z') of the cell impedance were measured in ohms for various frequencies. The impedance values $[\log (\mathrm{z} / \mathrm{ohm})]$ were derived from Bode plots.

\section{Cyclic voltammetry}

Cyclic voltammograms were recorded with the cell set up used for polarization study. The scan rate was $0.1 \mathrm{~V} / \mathrm{s}$. The graph between potential (V) vs. current (A) was plotted.

\section{Decolourisation process}

Decolourisation of a dye such as methyl orange was attempted using various electrodes such as stainless steel, stainless steel electroplated with zinc and 
stainless steel electroplated with zinc followed by blue passivation. The optical density of the methyl orange solution before and after decolourisation was measured by an instrument photoelectric colorimeter -112 . The electrodes were immersed in $100 \mathrm{~mL}$ of the solution containing $50 \mathrm{ppm}$ of methyl orange. The solution was subjected to electrochemical decolourisation process after addition of various concentrations of $\mathrm{NaCl}$. Graphite was used as cathode. Stainless steel, electroplated stainless steel, or stainless steel electroplated with zinc followed by blue passivation, were used as anode. The electrolysis was carried out in an undivided cell with a stirring bar.

The $\%$ of decolourisation efficiency (DE) was calculated using the relation

$\mathrm{DE}=\left(\mathrm{OD}_{1}-\mathrm{OD}_{2}\right) \times 100 / \mathrm{OD}_{1}$

where $\mathrm{OD}_{1}$ and $\mathrm{OD}_{2}$ are optical densities before and after decolourisation, respectively.

\section{Results and discussion}

\section{Analysis of results of weight loss method}

Corrosion rates obtained by weight loss method of stainless steel (SS) samples, before and after electroplating, in an aqueous solution containing 3.5\% $\mathrm{NaCl}$, and of stainless steel electroplated with zinc followed by blue passivation, are given in Table 1. It is observed that when stainless steel is electroplated with zinc, the corrosion rate increased from 6.36 mdd to 16.36 mdd. This suggests that the corrosion resistance of stainless steel decreases after zinc plating. This is due to the fact that the zinc film is broken in presence of $3.5 \% \mathrm{NaCl}$. Hence corrosion is accelerated. Further, when stainless steel 304 and zinc are in contact, zinc becomes anode and hence it undergoes corrosion [18]. But for stainless steel electroplated with zinc followed by blue passivation, the corrosion rate decreased from 16.36 mdd to $14.55 \mathrm{mdd}$. The corrosion rates presented in Table 1 reveal that the blue passivated stainless steel is more corrosion resistant than zinc coated stainless steel, but it is less corrosion resistant than the stainless steel itself.

Table 1. Corrosion rates (CR) of metal specimens immersed in $3.5 \% \mathrm{NaCl}$ solution.

\begin{tabular}{lcc}
\hline Sample & $\mathrm{NaCl} / \%$ & $\mathrm{CR} / \mathrm{mdd}$ \\
\hline $\mathrm{SS}$ & 3.5 & 6.36 \\
$\mathrm{SS}+\mathrm{Zn}$ & 3.5 & 16.36 \\
$\mathrm{SS}+\mathrm{Zn}+\mathrm{BP}$ & 3.5 & 14.55 \\
\hline Stainless steel; CR: Corrosion rate (milligram $/ \mathrm{dm}^{2}$. day); BP: Blue Passivation
\end{tabular}

\section{Action of 1\% copper sulphate solution on the metal surface}

The time for the appearance of reddish brown solution, when a drop of $1 \%$ copper sulphate solution was placed on the metal surface, before and after electroplating, is given in Table 2 . 
Usually, when a drop of $1 \%$ copper sulphate solution is placed on polished carbon steel surface (CS), a red colour appears. The formation of red colour is due to the conversion of blue $\mathrm{Cu}^{2+}$ ion into $\mathrm{Cu}$ which is red in colour.

$$
\mathrm{Cu}^{2+}+\mathrm{Fe} \rightarrow \mathrm{Fe}^{2+}+\mathrm{Cu}(\mathrm{red})
$$

When one drop of $1 \%$ copper sulphate was placed on the carbon steel surface, a red solution appeared within 65 seconds. This is due to the fact that blue $\mathrm{Cu}^{2+}$ ion is reduced to red $\mathrm{Cu}$ because of electron transfer from $\mathrm{Fe}$ to $\mathrm{Cu}^{2+}$.

When one drop of $1 \%$ copper sulphate solution was placed on stainless steel surface, red colour did not appear even after 1200 seconds. But blue colour disappeared immediately. A colourless solution was obtained.

This may be explained by the fact that there is formation of colourless $\mathrm{Cu}^{+}$ion. This $\mathrm{Cu}^{+}$ion is produced by interaction of blue $\mathrm{Cu}^{2+}$ ion and the one electron that comes from the metal surface. This electron may come from $\mathrm{Ni}$ or $\mathrm{Cr}$ or $\mathrm{Fe}$ present in the stainless steel 304.

$$
\mathrm{Cu}^{2+}+\mathrm{e}^{-} \rightarrow \mathrm{Cu}^{+}(\text {colourless })
$$

Similarly, when one drop of $1 \%$ copper sulphate was placed on stainless steel surface coated with zinc, red colour did not appear even after 1200 seconds. But blue colour disappeared immediately. A colourless solution was obtained.

This may be explained by the fact that there is formation of colourless $\mathrm{Cu}^{+}$ion. This $\mathrm{Cu}^{+}$ion is produced by interaction of blue $\mathrm{Cu}^{2+}$ ion and the one electron that comes from the metal surface. This electron may come from $\mathrm{Ni}$ or $\mathrm{Cr}$ or $\mathrm{Fe}$ or $\mathrm{Zn}$ present in the stainless steel 304 or zinc coated stainless steel.

Similarly, when one drop of $1 \%$ copper sulphate was placed on stainless steel surface coated with zinc followed by blue passivation, red colour did not appear even after 1200 seconds. But blue colour disappeared at 185th second. A colourless solution was obtained. This is because when zinc is electroplated on stainless steel, zinc becomes less noble and it undergoes corrosion and stainless steel is protected [18].

Table 2. Time required for the appearance of reddish brown deposit when one drop of $1 \% \mathrm{CuSO}_{4}$ solution was placed on the metal surface before and after electroplating.

\begin{tabular}{lcc}
\hline Metal & Time & Inference \\
\hline $\mathrm{CS}$ & Red colour appears at $65^{\text {th }}$ second & $\mathrm{Cu}^{2+}$ reduced to $\mathrm{Cu}$ \\
$\mathrm{SS}$ & $\begin{array}{c}\text { Blue colour disappeared immediately } \\
\text { Red colour did not appear }\end{array}$ & $\mathrm{Cu}^{2+}$ reduced to $\mathrm{Cu}^{+}$ \\
$\mathrm{SS}+\mathrm{Zn}$ & $\begin{array}{c}\text { Blue colour disappeared immediately } \\
\text { Red colour did not appear }\end{array}$ & $\mathrm{Cu}^{2+}$ reduced to $\mathrm{Cu}^{+}$ \\
$\mathrm{SS}+\mathrm{Zn}+\mathrm{BP}$ & $\begin{array}{c}\text { Blue colour disappeared at } 185^{\text {th }} \text { second } \\
\text { Red colour did not appear }\end{array}$ & $\mathrm{Cu}^{2+}$ reduced to $\mathrm{Cu}^{+}$ \\
& & \\
\hline
\end{tabular}

\section{Analysis of potentiodynamic polarization study}

The polarization curves of stainless steel (SS), stainless steel electroplated with zinc, and stainless steel electroplated with zinc followed by blue passivation immersed in an aqueous solution containing 3.5\% NaCl, are shown in Fig. 1a, 1b 
and 1c. The corrosion parameters such as corrosion potential $\left(\mathrm{E}_{\mathrm{corr}}\right)$, Tafel slopes $\left(b_{c}=\right.$ cathodic $)\left(b_{a}=\right.$ anodic $)$, linear polarization resistance (LPR) and corrosion current $\left(\mathrm{I}_{\text {corr }}\right)$, are given in Table 3. When stainless steel was immersed in an aqueous solution containing $3.5 \% \mathrm{NaCl}$, the corrosion potential was $-198 \mathrm{mV}$ vs. SCE. When stainless steel was electroplated with zinc, the corrosion potential was shifted to cathodic side $-1043 \mathrm{mV}$. This is due to the deposition of $\mathrm{Zn}$ on SS surface [17] so that metal surface becomes more active and hence undergoes corrosion. The LPR value decreases from $503.9 \times 10^{1} \mathrm{ohm} \mathrm{cm}^{2}$ to $5.128 \times 10^{1} \mathrm{ohm}$ $\mathrm{cm}^{2}$ for SS 304 coated with zinc. The corrosion current increases from $6.827 \times 10^{-6}$ to $636.0 \times 10^{-6} \mathrm{~A} / \mathrm{cm}^{2}$. Decrease in LPR value and increase in the corrosion current suggest that the effective protective film had not been formed on stainless steel electroplated with zinc [19-20]. These observations suggest that the corrosion protecting efficiency decreases when SS is electroplated with Zn and the corrosion rate increases. This suggests that zinc film coated on SS is easily broken when in $3.5 \% \mathrm{NaCl}$ solution. This enhances the corrosion rate of iron in SS, as sodium chloride solution enters into the pores created by the breaking of zinc film coated on SS surface.

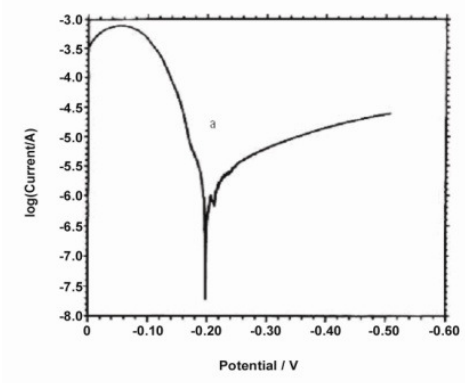

(a)

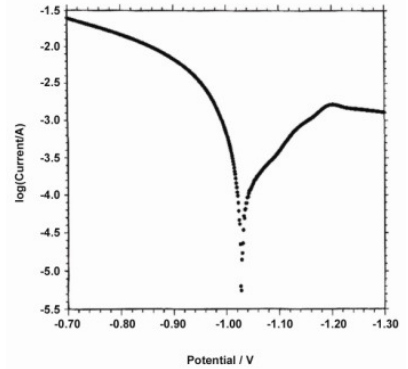

(b)

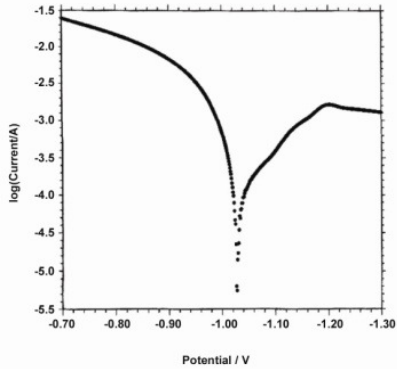

(c)

Figure 1. Polarisation curves of stainless steel (a) without further treatment, (b) electroplated with zinc and (c) electroplated with zinc followed by blue passivation, immersed in an aqueous solution containing 3.5\% NaCl.

When stainless steel electroplated with zinc followed by blue passivation was immersed in an aqueous solution containing $3.5 \% \mathrm{NaCl}$, the corrosion potential was $-1028 \mathrm{mV}$, which is cathodic when compared to stainless steel, but it is slightly anodic when compared with zinc coated stainless steel. The LPR value of stainless steel electroplated with zinc followed by blue passivation was $9.238 \times 10^{1} \mathrm{ohm} \mathrm{cm}^{2}$. The corrosion current value for stainless steel electroplated with zinc followed by blue passivation increased to $369.7 \times 10^{-6} \mathrm{Alcm}^{2}$. The decrease in the LPR value and the increase in the corrosion current suggest that the blue passivated stainless steel is more corrosion resistant than the stainless steel electroplated with zinc; but it is less corrosion resistant than stainless steel itself. The corrosion resistance of SS is better than SS coated with zinc, and than SS coated with zinc followed by blue passivation, as revealed by higher LPR value and lower current. 
Table 3. Corrosion parameters of stainless steel (SS) samples immersed in an aqueous solution containing 3.5\% NaCl, before and after electroplating. (Obtained from potentiodynamic polarization study).

\begin{tabular}{lccccc}
\hline Sample & $\begin{array}{c}\mathrm{E}_{\text {corr }} \\
(\mathrm{mV} \text { vs. SCE })\end{array}$ & $\begin{array}{c}\mathrm{b}_{\mathrm{c}} \\
(\mathrm{mV})\end{array}$ & $\begin{array}{c}\mathrm{b}_{\mathrm{a}} \\
(\mathrm{mV})\end{array}$ & $\begin{array}{c}\text { LPR } \\
\left.(\mathrm{ohm} \mathrm{cm})^{2}\right)\end{array}$ & $\begin{array}{c}\mathrm{I}_{\text {corr }} \\
\left(\mathrm{A} / \mathrm{cm}^{2}\right)\end{array}$ \\
\hline SS & -198 & 233 & 120 & 5039 & $6.827 \times 10^{-6}$ \\
SS+Zn & -1043 & 133.4 & 172 & 51.28 & $636.0 \times 10^{-6}$ \\
SS+Zn+BP & -1023 & 146.4 & 170 & 92.38 & $369.7 \times 10^{-6}$ \\
\hline
\end{tabular}

Hence, it is suggested that stainless steel coated with zinc should not be used in coastal area, ships and shipyards, and also for storing thiourea in industries [17]. Otherwise machines, made of this combination will undergo corrosion because of the chloride vapours present in coastal area.

\section{Analysis of AC impedance spectra}

The AC impedance spectra (Bode plots) of stainless steel electroplated with zinc followed by blue passivation immersed in an aqueous solution containing 3.5\% $\mathrm{NaCl}$ are shown in Fig. 2a, 2b and 2c. The real impedance [log (z/ohm)] values are given Table 4. It was observed that when stainless steel was immersed in $3.5 \% \mathrm{NaCl}$ solution the real impedance value was 2.05. After zinc deposition this value decreased to 1.46. For blue passivated stainless steel the real impedance value was 1.49 .

The decrease in the real impedance value for electroplated $(\mathrm{Zn})$ stainless steel, 1.46, when compared to stainless steel, 2.05, shows that corrosion is accelerated in the case of zinc plated stainless steel; but the value 1.49 for blue pasivated stainless steel suggests that the blue passivated stainless steel is more corrosion resistant than zinc coated stainless steel, but less corrosion resistant than the stainless steel itself.
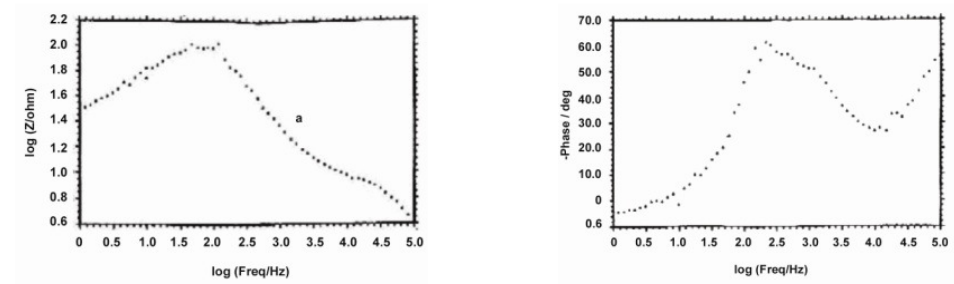

Figure 2a. AC impedance spectra of stainless steel immersed in an aqueous solution containing $3.5 \% \mathrm{NaCl}$ (Bode plot).
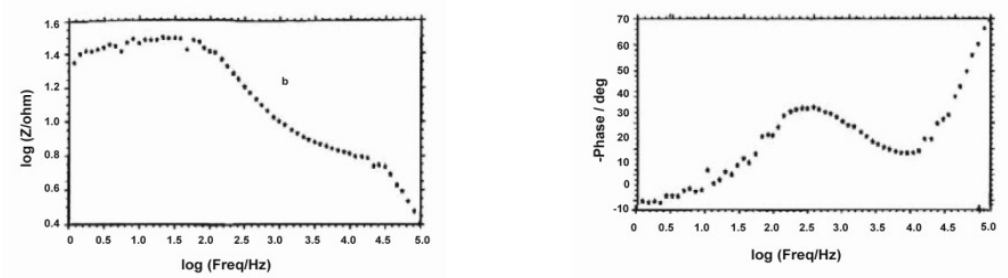

Figure 2b. AC impedance spectra of stainless steel electroplated with zinc immersed in an aqueous solution containing 3.5\% $\mathrm{NaCl}$ (Bode plot). 

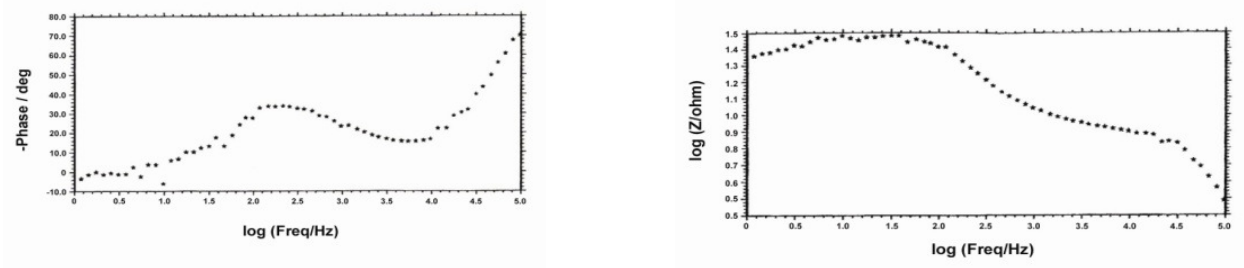

Figure 2c. AC impedance spectra of stainless steel electroplated with zinc followed by blue passivation immersed in an aqueous solution containing 3.5\% $\mathrm{NaCl}$ (Bode plot).

Table 4. AC impedance parameters of stainless steel (SS) samples immersed in an aqueous solution containing $3.5 \% \mathrm{NaCl}$, before and after electroplating (obtained from Bode plot).

\begin{tabular}{lc}
\hline Sample & Real impedance, $\log (\mathrm{z} /$ ohm $)$ \\
\hline SS & 2.05 \\
SS+Zn & 1.46 \\
SS+Zn+BP & 1.49 \\
\hline
\end{tabular}

\section{Analysis of cyclic voltammograms}

The cyclic voltammograms of stainless steel, stainless steel electroplated with zinc, and stainless steel electroplated with zinc followed by blue passivation, immersed in an aqueous solution containing 3.5\% NaCl, are shown in Fig. $3 \mathrm{a}, 3 \mathrm{~b}$ and 3c. It was observed that redox couples were absent in these cyclic voltammograms.

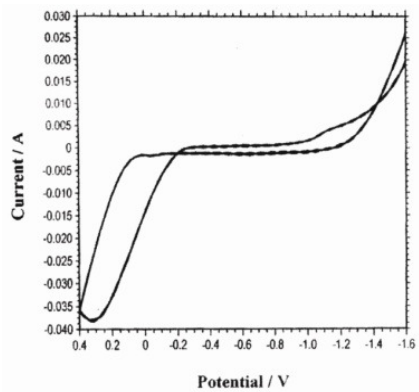

(a)

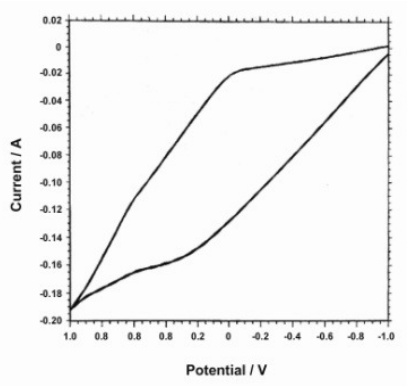

(b)

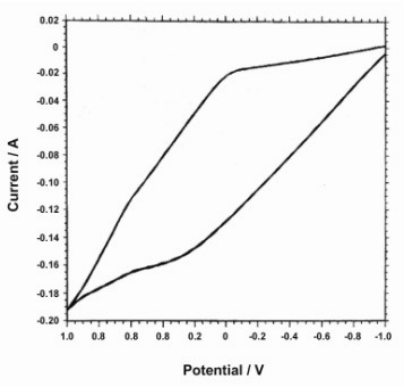

(c)

Figure 3. Cyclic voltammograms of stainless steel (a) without further treatment, (b) electroplated with zinc and (c) electroplated with zinc followed by blue passivation, immersed in an aqueous solution containing 3.5\% NaCl.

\section{Decolourisation process}

Decolourisation using stainless steel

The efficiency of decolourisation of methyl orange $(50 \mathrm{ppm})$ is given in Table 5. Uncoated stainless steel anode and graphite cathode were immersed in the solution to decolourise $50 \mathrm{ppm}$ of methyl orange solution. The solution was electrolysed for 10 minutes without addition of $\mathrm{NaCl}$. There was no decolourisation. The experiment was repeated after addition of $7 \mathrm{~g}$ of $\mathrm{NaCl}$ and the solution was electrolysed. The current density was $1.3 \mathrm{~A} / \mathrm{cm}^{2}$ and the 
potential was 3.8 Volts. Methyl orange solution was completely decolourised within 157 seconds. The efficiency of decolourisation was $95 \%$.

Table 5. Efficiency of decolourization of methyl orange (50 ppm). Optical density for methyl orange $=0.42$.

\begin{tabular}{lcccc}
\hline Sample & Time $(\mathrm{s})$ & Current $\left(\mathrm{A} / \mathrm{cm}^{2}\right)$ & Potential $(\mathrm{V})$ & DE $(\%)$ \\
\hline SS & 157 & 1.3 & 3.8 & 95 \\
SS+Zn & 249 & 1 & 2.5 & 88 \\
SS+Zn+BP & 241 & 0.85 & 1 & 83 \\
\hline \multicolumn{2}{c}{ DE -Decolourisation Efficiency } & & &
\end{tabular}

Decolourisation using stainless steel electroplated with zinc

The experiment was repeated by using stainless steel electroplated with zinc after addition of $7 \mathrm{~g}$ of $\mathrm{NaCl}$; the solution was electrolysed. The current density was 1 $\mathrm{A} / \mathrm{cm}^{2}$ and the potential was 2.5 Volts. Methyl orange solution was decolourised within 249 seconds. The efficiency of decolourisation was $88 \%$. When $\mathrm{NaCl}$ solution was electrolysed, the active species produced is $\mathrm{Cl}^{+}$[21-23]. This oxidized the coloured material into colourless product. (Scheme1).

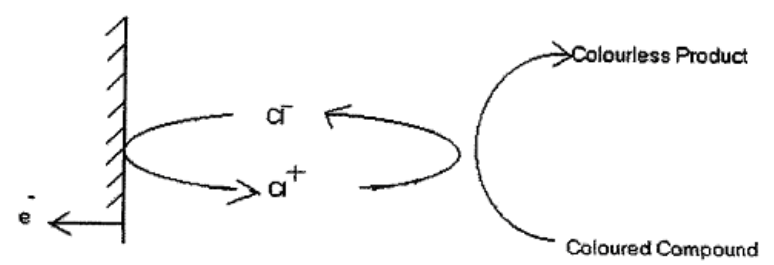

Scheme 1. Mechanism of decolourisation.

Decolourisation using stainless steel electroplated with zinc followed by blue passivation

The experiment was repeated by using stainless steel electroplated with zinc and blue passivation, after addition of $7 \mathrm{~g}$ of $\mathrm{NaCl}$. The solution was electrolysed. The current density was $0.85 \mathrm{~A} / \mathrm{cm}^{2}$ and the potential was 1 Volt. Methyl orange solution was decolourised within 241 seconds. The efficiency of decolourisation was only $83 \%$.

The decolourisation efficiency is in the order $\mathrm{SS}>\mathrm{SS}+\mathrm{Zn}>\mathrm{SS}+\mathrm{Zn}+\mathrm{BP}$. This suggests that the ease of electron release from the metal surface is in the order $\mathrm{SS}>\mathrm{SS}+\mathrm{Zn}>\mathrm{SS}+\mathrm{Zn}+\mathrm{BP}$.

\section{Conclusions}

Zinc was electro deposited on stainless steel 304 surface using the bath containing $\mathrm{ZnCl}_{2}, \mathrm{KCl}$ and boric acid. Then blue passivation was done. The corrosion protective efficiency of the film was evaluated by weight loss method, copper sulphate test, polarization and AC impedance studies. The zinc deposited stainless steel was used to decolourise methyl orange solution. 
When uncoated stainless steel 304 was immersed in an aqueous solution containing $3.5 \% \mathrm{NaCl}$, the corrosion rate was $6.36 \mathrm{mdd}$. But when zinc was deposited in SS 304, the corrosion rate increased to $16.36 \mathrm{mdd}$, but for blue passivated SS 304 the corrosion rate decreased to $14.55 \mathrm{mdd}$. This shows that SS 304 electroplated with zinc followed by blue passivation is more corrosion resistant than zinc electroplated SS 304.

Polarization study and AC impedance spectra lead to conclusion that when stainless steel is electroplated with zinc, corrosion is accelerated and corrosion protective efficiency was in the order $\mathrm{SS}>\mathrm{SS}+\mathrm{Zn}+\mathrm{BP}>\mathrm{SS}+\mathrm{Zn}$.

The metal specimens were used to decolourise $50 \mathrm{ppm}$ of methyl orange solution and the decolourising efficiency was in the order $\mathrm{SS}>\mathrm{SS}+\mathrm{Zn}>\mathrm{SS}+\mathrm{Zn}+\mathrm{BP}$.

Hence stainless steel coated with zinc should not be used in coastal area, in ships and shipyards.

\section{Acknowledgement}

The authors are thankful to their respective managements, St. Joseph's Research and Community Development Trust, Dindigul and University Grants commission, India, for their help and encouragement.

\section{References}

1. M.K. Karfoul, "Industrial Corrosion and Corrosion Control Technology", H.M. Shalaby, A. Al-Hashem, M. Lowther, J. Al-Besharak (Eds.), Kuwait Inst. Sci. Research, Safat, 1996. p. 431- 439.

2. E.C. Bain, R.H. Aborn, J.J.B. Rutherford, "The Nature and Prevention of Intergranular Corrosion in Austenitic Stainless Steel”, Trans. Am. Soc. Steel Treating, 1993. Vol.XXI, No.1, p.481-509.

3. E.C. Potter, G.M.W. Mann, "Oxidation of Mild Steel in High Temperature Aqueous System", $1^{\text {st }}$ Int. Congress on Metallic Corrosion", 10-15 April (1961), p. 417.

4. G.M.W. Mann, "High - temperature, High- pressure Electrochemistry in Aqueous Solutions", Tx: NACE International, Houston, (1976), p.36.

5. L. Tomlinson, Corrosion 37 (1981) 591.

6. H. Tsuchiya, M. Hueppe, T. Djenizian, P. Schmuki, Appl. Surf. Sci. 547 (2003) 268.

7. H. Tsuchiya, M. Hueppe, T. Djenizian, P. Schmuki, S. Fujimoto, Sci.Tech. Adv.Mater. 5 (2004) 195.

8. H. Tsuchiya, P. Schmuki, J. Electrochem. Comm. 7 (2005) 49-52.

9. D. Gong, C.A. Grimes, O.K. Varghese, W. Hu, R.S. Singh, Z. Chen, E.C. Dickey, J. Mater. Res. 16 (2001) 3331.

10. V. Zwilling, E. Darque-Ceretti, A. Boutry-Forveille, Electrochim. Acta 45 (1999) 921.

11. S.S. Chang, S. Kurokawa, A. Sakai, Appl. Surf. Sci. 217 (2003) 50.

12. S.S. Chang, C.H. Park, S.W. Park, Mater. Chem. Phys. 79 (2003) 9.

13. H.C. Shin, J. Dong, M. Liu, Adv. Mater.16 (2004) 237. 
14. R. Beranek, H. Hildebrand, P. Schmuki, Electrochem. Solid-state Lett. 6 (2003) 312.

15. A.M. Lekka, A.N. Koulombi, B.M. Gajo, J.P.L. Bonora, Electrochim. Acta 50 (2005) 4551-4556.

16. I. Gurappa, Mater. Charact. 49 (2002) 73-79.

17. S. Rajendran, V. Agnes Brigita, J. Manivannan, J. Jeyasundari, Port. Electrochim. Acta 27 (2009) 555-564.

18. G.M. Fontana, "Corrosion Engineering”, Mc Graw-Hill, 3rd Ed., New York, 2006. p.43.

19. S. Rajendran, J. Paulraj, P. Rengan, J. Jeyasundari, M. Manivannan, J. Dentistry Oral Hygiene 1 ( 2009) 1-8.

20. S. Rajendran, V. Uma, A. Krishnaveni, J. Jeyasundari, B. Shymaladevi, M. Manivannan, Arab. J. Sci. Eng. 34 (2009) 147-158.

21. J. Sathiyabama, S. Rajendran, J.Arockiaselvi, Bull. Electrochem. 22 (2006) 363-369.

22. S. Rajendran, D.C. Trivedi, J. Synth. 2 (1995)153.

23. R.L. Doston, R.W. Lynch, J. Electrochem. Soc. 128 (1981) 798. 